\title{
Taking Stock of the Consortium ${ }^{1}$
}

\section{Peter Foot}

My task in this introductory essay is to remind ourselves what the Partnership for Peace Consortium has become and, by doing so, to give those new to our activities a view of what we are. The point here is not to defend the Consortium, but rather to show what the Consortium does to add value. After all, the EAPC is full of military academies; and, as for research institutes, it just takes a web address, a phone number, letterhead, and, of course-that guarantee of wealth and immortality - an expensively designed logo. Does the Consortium pass the "So what?" test? What is the "value added" of the Consortium to the security community of the EAPC? What makes it precious and worth our while?

While the answers to these questions could be voluminous, I have selected what I think are the seven most salient explanations of the Consortium's value.

- Nowhere else do national officials, both uniformed and civilian, meet with experts from universities and research institutions, and do so across the whole of the EAPC.

- This unique confluence of individuals has led to the distinctive dynamism that comes from organizing contacts, expertise, and research from the bottom up. The Consortium is an equal-opportunity, talent-based organization - no new participant is in any way disadvantaged by virtue of having just arrived.

- No other institution so actively recruits scholars from Central and Eastern Europe and from the Caucasus and Central Asia. These regions are fundamental to the security debate; their societies are those most in transition and whose concerns are both so significantly under-represented in mainstream discussion and so central to the EAPC's overall security. Among the best work in the Consortium emerges from partnerships between these scholars and those from more established Western foundations.

- Another fruitful partnership hosted here better than elsewhere is that between political scientists and historians. The end of the Cold War reemphasized the relevance of history to policy-relevant research. Interdisciplinary synergies of the kind that have already been achieved are not institutionally encouraged elsewhere as they are within the Consortium.

\footnotetext{
${ }^{1}$ This is an edited version of the address given by the author at the Consortium's Annual Conference in Berlin, June 2003. Peter Foot is the Deputy Dean of Academic Studies at the Joint Services Command and Staff College, United Kingdom.
} 
- Only the Consortium provides a multi-disciplinary context for the creativity that emerges from the partnership between traditional modes of scholarship and new technologies and methodologies.

- Similarly, the Consortium is the primary international space where security research directly informs military education and training. In no modern period has there been as great a need as there is now to bring the best of strategic thinking rapidly into the training arena.

- Finally, the Consortium encompasses the entire spectrum of the security field, from higher strategic thought to hands-on, real-time operational training for soldiers in the field, and for a variety of international command levels.

It hardly needs to be added to this list of special value-added elements the fact that the Consortium is the only entity that does them all.

Lord Robertson called recently for a "revolution in strategic education"-a phrase that could have been invented with the PfP Consortium in mind. He is not only right to issue this call but also to bring attention to bear on the content and quality of the teaching of the profession of arms across the EAPC. Quite simply, the Consortium offers the best opportunities for integrating new strategic thought directly into professional military education. But "value added" lists need to be applied practically if their potential is to be realized. The Consortium can do this in a number of ways.

- First, it can sustain its publications and web site to the highest standards. These are the tangible outputs of the organization and can be developed further as a tool for the use of all participants. All Working Groups are encouraged to contact me with publishing proposals. Material that will assist the defense academies in fulfilling Lord Robertson's revolutionizing initiative will be especially welcome.

- Second, as others have suggested, the governance structure of the Consortium needs to be reviewed in the light of the new security agenda. Conditions change, and structures sometimes need to be adapted to maximize their effectiveness.

- Third, some of that change has taken place already; the new structure of the Annual Conference marks a useful development. The streamlining of the organization in September 2002 and this Conference's four study themesEducation and Training, Civil-Military Relations, Crisis Management and Regional Stability, and Countering Terrorism-work well to showcase the work that has been done over the previous year and provide useful leading thoughts for the year ahead. 
- Fourth, the main sponsoring parties need to allay the uncertainties that changes in government priorities can sometimes bring to a multinational organization such as ours. Budgetary doubts help no one; the point for the Consortium is to measure its success against the benchmark of effectiveness. If that is done responsibly and well, questions about finances will take their proper place.

- Fifth, the Consortium can take steps to ensure that it remains the main security education and research link between the countries of NATO; the candidate NATO members, who are at different stages of the membership process; and those countries that remain in the PfP and have no intention of moving towards formal Alliance membership. Other opportunities exist for this as well, notably the PfP/NATO Conference of Commandants and the NATO Defense College, and the Consortium needs to bring its unique education-research relationship more to bear on those activities.

- Finally, and perhaps most importantly, the dynamism of the Consortium comes from the Working and Study Groups. This is truly a bottom-up organization. It is in those groups that synergies happen, trans-national links are made, research and teaching partnerships forged. This is not the place for rigid top-down agendas: by definition, such an approach would leave policy makers the prisoners of outdated ideas, and therefore ultimately lead again to strategic surprise.

All of these goals are readily achieved. The Secretariat Working Group will consider the outcome of this Conference, and the content of these and other suggestions, at its meeting in September. It will immediately inform the co-chairs of the Working Groups and help disseminate upward the decisions that are arrived at on behalf of the entire group. The Consortium will, in short, continue to be what it set out to be at its creation: a multi-national coalition of willing democracies conducting security research and educational programs for military practitioners, defense employees, career diplomats, and security studies academics. Changes must and will be made, but the core of its activities is unique, central, and indispensable. 